Research Article

\title{
Effect of Severity Factor on the Subcritical Water and Enzymatic Hydrolysis of Coconut Husk for Reducing Sugar Production
}

\author{
Maktum Muharja $^{1}$, Nur Fadhilah ${ }^{2}$, Rizki Fitria Darmayanti ${ }^{1}$, Hanny Frans Sangian ${ }^{3}$, \\ Tantular Nurtono ${ }^{4}$, Arief Widjaja ${ }^{4, *}$
}

${ }^{1}$ Department of Chemical Engineering, Faculty of Engineering, Universitas Jember, Jember 68121, Indonesia.

${ }^{2}$ Department of Engineering Physics, Institut Teknologi Sepuluh Nopember, Sukolilo, Surabaya, East Java 60111, Indonesia.

${ }^{3}$ Department of Physics, Faculty of Mathematics and Natural Sciences, Universitas Sam Ratulangi, Manado 95115, Indonesia.

${ }^{4}$ Department of Chemical Engineering, Institut Teknologi Sepuluh Nopember, Surabaya 60111, Indonesia.

Received: $4^{\text {th }}$ September 2020; Revised: 17th October 2020; Accepted: $17^{\text {th }}$ October 2020; Available online: 28th October 2020; Published regularly: December 2020

\section{Abstract}

Preventing the further degradation of monomeric or oligomeric sugar into by-product during biomass conversion is one of the challenges for fermentable sugar production. In this study, the performance of subcritical water (SCW) and enzymatic hydrolysis of coconut husk toward reducing sugar production was investigated using a severity factor (SF) approach. Furthermore, the optimal condition of SCW was optimized using response surface methodology (RSM), where the composition changes of lignocellulose and sugar yield as responses. From the results, at low SF of SCW, sugar yield escalated as increasing SF value. In the enzymatic hydrolysis process, the effect of SCW pressure is a significant factor enhancing sugar yield. A maximum total sugar yield was attained on the mild SF condition of 2.86 . From this work, it was known that the SF approach is sufficient parameter to evaluate the SCW and enzymatic hydrolysis of coconut husk. Copyright (C) 2020 BCREC Group. All rights reserved

Keywords: coconut husk; enzymatic hydrolysis; reducing sugar; severity; subcritical water

How to Cite: Muharja, M., Fadhilah, N., Darmayanti, R.F., Sangian, H.F., Nurtono, T., Widjaja, A. (2020). Effect of Severity Factor on the Subcritical Water and Enzymatic Hydrolysis of Coconut Husk for Reducing Sugar Production. Bulletin of Chemical Reaction Engineering \& Catalysis, 15(3), 786-797 (doi:10.9767/bcrec.15.3.8870.786-797)

Permalink/DOI: https://doi.org/10.9767/bcrec.15.3.8870.786-797

\section{Introduction}

Over the past decades, due to the significance of generating renewable clean energy, the techniques of fermentable sugar production are

\footnotetext{
* Corresponding Author.

Email: arief_w@chem-eng.its.ac.id (A. Widjaja);

Telp: +62-31-5946240, Fax: +62-31-5999282
}

the subject of exhaustive research to produce bioethanol, biogas, and biohydrogen [1-3]. Fermentable sugar can be produced from potential lignocellulose waste, such as: coconut husk, which contains cellulose and hemicellulose in high levels [4]. Moreover, the abundant annual production of coconut husk allows this waste to be used for industrial-scale in Indonesia [5]. However, the high lignin content of $41.19 \%$ in 
coconut husk causes ineffective enzyme accessibility, resulting in decreasing fermentable sugar production [6].

Supercritical fluid technology, as the latest technology for hydrolysis and extraction, become the promising method to be developed [710]. Subcritical water (SCW), the most moderate process of supercritical fluid, is well-known to be able to break down the complex lignin of biomass efficiently and has been proven to be technically feasible instead of the acid/base method due to its advantages, namely short time, less corrosion and environmentally friendly [11-13]. One of the challenges of the SCW process is the further degradation of glucose and other oligomers, which are faster than the cellulose decomposition rate by an increase of severity condition [14-16]. Hence, the operating conditions of SCW should be optimized to obtain sugar and reduce operating costs.

Generally, the operating conditions of SCW were evaluated by one-by-one factors separately [17-20]. Severity factor (SF) parameter has been widely utilized to identify the effect of time, temperature, and $\mathrm{pH}$ parameters from the pretreatment process to maximize the degree of liquid biomass and sugar yield [21,22]. SF has been successfully applied for any kind of pretreatment method: hydrothermal [23,24], steam explosion [25,26], and hydrothermal with adding acid catalyst [27]. For enhancing the efficiency of the process, SCW can be evaluated using the severity factor (SF) level, which relates to the parameter combination of reaction time, temperature, and $\mathrm{pH}$ [28-30]. Under mild conditions, the subcritical process produces a longer chain oligomer, which decreases in length by increasing the severity factor [23,30]. However, sugar degradation simultaneously escalates as severity increases. The precision control of severity should be conducted to minimize the formation of inhibitor components, such as: furfural and acid compound as well as maximize sugar hydrolysis $[21,31]$.

From previous work, one of the attractive gas for further investigation of the SCW process is nitrogen because of its low price and inert property [5,32]. The study of nitrogen as pressurizing gas at SCW has been studied by previous researchers that only focus on medium to high severity of the hydrothermal process $[32,33]$. From the reviewed literature, no previous works that studied the severity behavior of the nitrogen pressurized-SCW process on the hydrolysis of coconut husk.

As the problem mentioned earlier, the objective of this research is to evaluate the severity of the process parameter of SCW and enzymatic hydrolysis towards reducing sugar yield. The effect of SF on sugar production, holocellulose removal, and treated coconut husk structure was investigated.

\section{Materials and Methods}

\subsection{Materials}

$\mathrm{CCH}$ used in this work was collected from Manado City, North Sulawesi, Indonesia. The physical treatment before the SCW process was adapted from Muharja et al. [5]. Dinitro salicylic acid (DNS) and other chemicals were purchased from Sigma Aldrich, Japan.

\subsection{Methods}

\subsubsection{SCW process}

Six grams of coconut husk was mixed with $120 \mathrm{~mL}$ distilled water inside the stainless reactor, as described by Muharja et al. [32]. The temperature was increased until the subcritical condition of the water attained. Temperatures were varied at $110-190{ }^{\circ} \mathrm{C}$; the pressure of ultra-high purity (UHP) nitrogen $\left(\mathrm{N}_{2}\right)$ (PT. Aneka Gas, Sidoarjo, Indonesia) was maintained at $20-80$ bar for 20-60 min. SCW process was run by using a batch operation. SCW pressurized by carbon dioxide $\left(\mathrm{CO}_{2}\right)$ gas was also utilized in this study to evaluate the type of pressurizing gas. All experiments were carried out in a triplicate run.

Sugar yield data in this study are presented as $\mathrm{SF}$ values, which combine the effects of temperature and time parameters of the pretreatment process into one equation (see Figure 1). The proportion between temperature and time, also known as severity, is a crucial factor in the

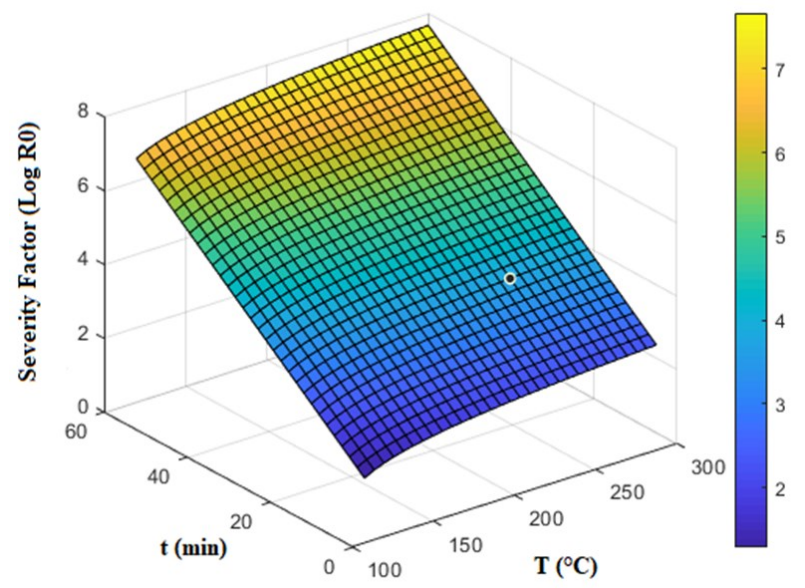

Figure 1. Representation of severity factor as the relationship of the temperature and time of SCW condition used in this study. 
pretreatment process. The $R_{0}$, severity factor, is expressed using a log function, as shown in Eq. (1), where $t$ corresponds to the reaction time, and $T$ is the SCW temperature [21]. Moreover, sugar yield was defined by Eq. (2).

$$
\log R_{0}=\log \left[t \exp \left(\frac{(T-100)}{14.75}\right)\right]
$$

Sugar yield $(\%)=\left(\frac{\text { mass of sugar obtained by DNS }(g)}{\text { mass of initial coconut husk }(g)}\right) \times 100$

\subsubsection{Optimal process conditions in the SCW} process

Box-Behnken design with five replicates at the center point was applied to optimize the critical factor to enhance reducing sugar production in the SCW process. Optimization was conducted only in the range of mild to high severity level. The effect of three independent variables (temperature $\left(X_{1}\right)$, time $\left(X_{2}\right)$, and pressure $\left(X_{3}\right)$ ) at three levels ( $X_{1}$ from 150 to 190, $X_{2}$ from 20 to $60 \mathrm{~min}$, and $X_{3}$ from 60 to 100 bar) on the reducing sugar concentration as the response was investigated by using Minitab 16 software package (Minitab Inc, ITS Surabaya, Indonesia). Fitting of the model and experimental data was evaluated by value of $R^{2}$.

\subsubsection{Enzymatic hydrolysis}

Enzymatic hydrolysis was subjected to the solid of SCW-treated at the low SF using commercial cellulase and xylanase (Sigma Aldrich, Japan) based on previous work conditions [34]. Enzymatic hydrolysis was conducted at a $\mathrm{pH}$ of 3 , the temperature of $60{ }^{\circ} \mathrm{C}$ in the modified incubator shaker, which was shaken at $125 \mathrm{rpm}$ and run for $48 \mathrm{~h}$.

\subsubsection{Analytical and characterization methods}

The SCW hydrolysis produced two products: the liquid and solid product. The reducing sugar of the liquid product was analyzed by employing the DNS method [35]. The chemical composition of the native coconut husk was analyzed using proximate analysis. The composition of hemicellulose was analyzed gravimetrically based on the previous method [5]. Furfural content was analyzed by a modified GC-FID method which was described previously by using GC-2010 Plus Shimadzu, Kyoto, Japan. [36]. Native and pretreated samples were examined by Scanning Electron Microscopy (SEM) Evo MA 19 (Carl Zeiss, England) to observe the microstructure of the sample and XRay Diffraction (XRD) to evaluate crystallinity index (CrI) of cellulose using X'Pert PRO (PANalytical B.V, Holland).

\section{Results and Discussion}

\subsection{Composition Analysis of Coconut Husk}

The results of chemical composition analysis (in mass percent) of coconut husk are shown in Table 1. The chemical property analysis is needed to predict the behavior and potential of coconut husk when used as a biofuel [37]. Crude fiber represents carbohydrates that are not easily digested, namely cellulose, hemicellulose and lignin. Meanwhile, nitrogen-free extract represents non-structural carbohydrates, such as: starch and monomer/oligomeric sugars [38].

More specifically, the hemicellulose and cellulose content in this study was $34.52 \%$. This result is close to the result of the study by Prado et al. [4], which consisting of polysaccharides glucans, xylan, galactant, arabinan, and mannan. From these results, it can be concluded that the sugar and holocellulose components contained in coconut husks have the potential to be converted into fermentable reducing sugars for biofuel production.

3.2 Severity Behavior of SCW Process Pressurized by $\mathrm{N}_{2}$

Figure 2 presents the effect of the severity factor (SF) of the SCW process pressurized by $\mathrm{N}_{2}$ gas on the sugar concentration following the SCW process. Sugar yield in this study is presented as a function of SF values. At low SF of

Table 1. Proximate analysis of the native coconut husk.

\begin{tabular}{ccccccc}
\hline Water content & Protein & Fat & CF & Ash & NFE & Reference \\
\hline $13.68 \pm 0.05$ & $5.77 \pm 0.39$ & $3.0 \pm 0.4$ & $69.6 \pm 5.51$ & $1.05 \pm 0.9$ & 6.9 & {$[38]$} \\
$14.46 \pm 0.05$ & $2.40 \pm 0.2$ & $1.5 \pm 0.3$ & $68.99 \pm 4.04$ & $0.92 \pm 0.01$ & 11.73 & {$[4]$} \\
$14.35 \pm 0.1$ & $3.06 \pm 0.3$ & $0.71 \pm 0.05$ & $74.57 \pm 3.2$ & $2.03 \pm 0.1$ & 5.28 & This study \\
\hline
\end{tabular}

Note: CF is Crude Fiber. NFE is a nitrogen-free extract 
2.07 to 3.05 , it is shown that sugar concentration increased from 0.5 to $3.8 \mathrm{~g} / \mathrm{L}$. Sugar concentration obtained at this range was proportional to the extracted hemicellulose. This result suggests that at this level, sugar was obtained from a monomer of hemicellulose only. This phenomenon was related to short and nonshaped polymer chains of hemicellulose that are relatively more straightforward to be hydrolyzed into its monomers, such as D-xylose, D-mannose, D-galactose, and L-arabinose [21].

Figure 2 also indicates that increasing SF to the mild severity of 3.83 caused the sugar concentration to be much larger than the hydrolyzed hemicellulose. This result indicated that in the mild severity condition, celluloses were also hydrolyzed into their monomers (i.e., glucose/cellobiose) by the increase of $\mathrm{H}_{3} \mathrm{O}^{+}$ions from water dissociation under SCW condition [36].

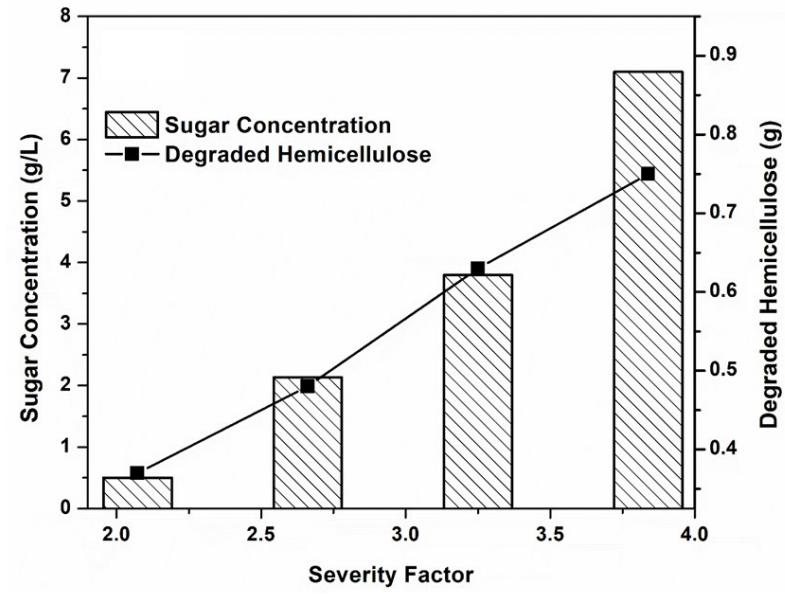

Figure 2. Effect of severity factor towards the sugar concentration obtained after SCW process.
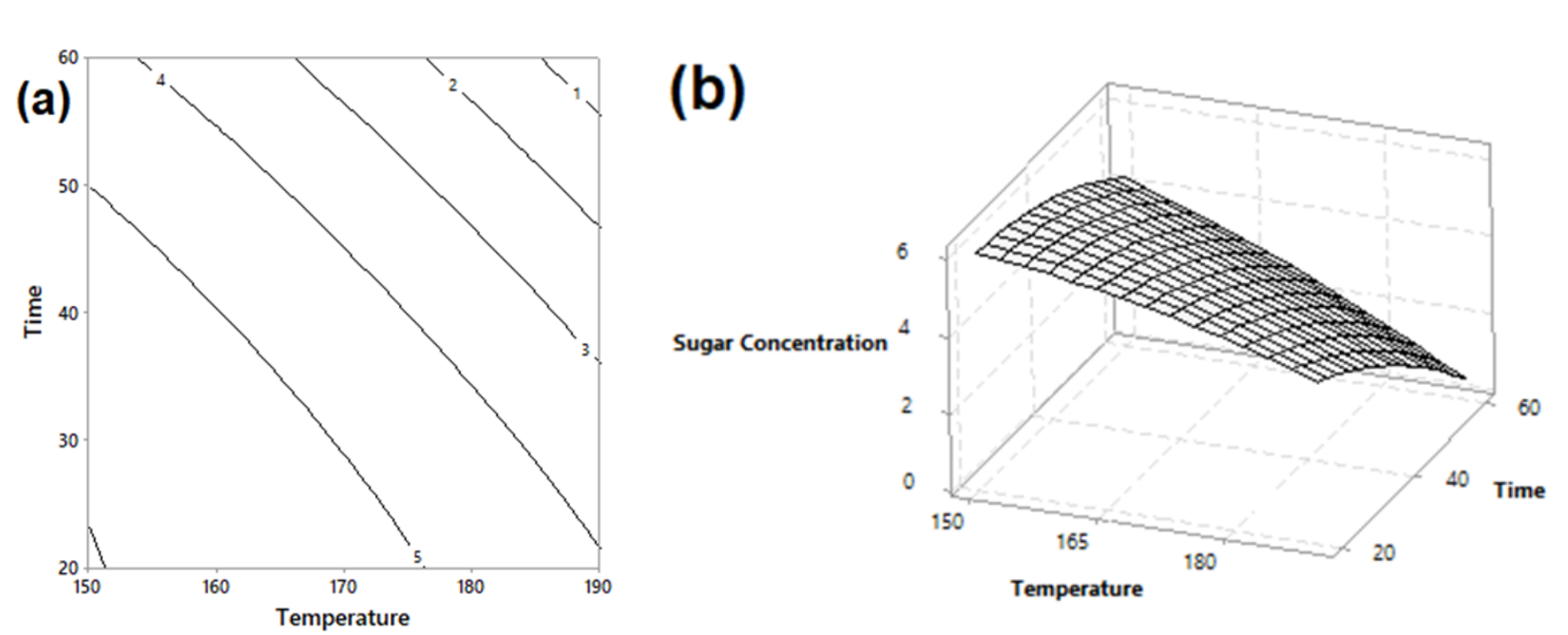

Figure 3. Contour (a) and response surface (b) of sugar concentration obtained after SCW process.
Response Surface Methodology (RSM) was conducted to investigate the interaction between the SCW severity parameter at mild to high SF condition. RSM is useful to determine the level of the parameters that contribute to the desired response [39]. Figure 3 is one of the plots of contour and response surface, which represented the most significant response. The plot of contour and response surface based on the independent variables of temperature $\left(X_{1}\right)$ and time $\left(X_{2}\right)$ where nitrogen pressure $\left(X_{3}\right)$ was kept at a medium level (80 bar) is illustrated in Figure 3. A maximum sugar was obtained when SCW temperature was maintained at a mild condition in the range of $150-154^{\circ} \mathrm{C}$. The highest sugar of $6.05 \mathrm{~g} / \mathrm{L}$ obtained at mild SF condition was $150{ }^{\circ} \mathrm{C}, 24.2 \mathrm{~min}$, and 80 bar (SF 2.86). Beyond this level, sugar concentration significantly decreased, which was attributed to the degradation of sugar under severe treatment conditions $[5,40]$. As shown in Figure 3a, the maximum sugar concentration was attained at a medium level of the reaction time of 20-30 min. However, extending the hydrolysis time leads to a gradual decrease in the obtained sugar, whereby it may be attributed to further sugar degradation due to excessive liquefaction levels [41,42].

The three-dimensional response surface contour plot was presented in Figure 3b. As shown in Figure 3b, the sugar concentration was significantly affected by severity condition (i.e. temperature and time) of the process (see also Table 2). The sugar concentration continuously decreased when the temperature increased. Increasing reaction time was also accompanied by decreasing sugar concentration. This decrease may occur due to further degradation of the sugar to compound at high tem- 
peratures [22]. The surface contour plot shows that the maximum sugar concentration region on the outside of mild to high severity condition.

Table 2 shows the results of the analysis of variance (ANOVA) for the concentration of reducing sugars after the SCW process. A low $P$ value (below 0.05) illustrates that reaction temperature and time have a significant effect on sugar concentration. A high $\mathrm{R}^{2}(0.865)$ indicates a good fitness of experimental data and predicted sugar concentrations. Meanwhile, the $P$ value at lack-of-fit above 0.05 means that there is compatibility with the model chosen. On the other hand, pressure does not have a significant effect on sugar concentration $(P>0.05)$. In general, by using ANOVA, it is known that temperature and time have a significant influence on sugar from the results of SCW, where reaction time is the most influential variable.

The highest sugar yield (12.1\%) after the SCW process in the present study was obtained at a mild level of SF of 2.86. Sugar yield performed in this study was able to compete with previous work, which used various substrate and pretreatment methods. In the comparison of substrates, rice straw was hydrolyzed by Lin et al. [33] using nitrogen assisted-SCW yielding
$34.6 \%$ sugar, which higher than this study, but it was obtained at high SF condition (SF 6.2). The yield obtained in this study was superior in mild conditions, which may prevent the degradation of sugar [21]. In a comparison of methods, Prado et al. [43] and Muharja et al. [5] used carbon dioxide as the pressurizing gas and obtained sugar yield higher than this study at SF 5.89 and 3.25, respectively. Nitrogen gas is preferred as pressurizing gas besides due to the economic aspect, $\mathrm{N}_{2}$ also showed a superior hydrolysis performance in extreme conditions because of its inert characteristic [32].

In this study, the highest furfural concentration, as the degradation product after SCW hydrolysis, was obtained at the highest SCW temperature of $170{ }^{\circ} \mathrm{C}$ (SF 3.84). The furfural content is $0.022 \mathrm{~g} / \mathrm{L}$. Zhang and Wu [44] reported that furfural concentration produced after subcritical $\mathrm{CO}_{2}$ pretreatment of eucalyptus at lower $\mathrm{SF}, 160{ }^{\circ} \mathrm{C}$ for $60 \mathrm{~min}$ (SF of 3.54), was lower than this study, which was $0.018 \mathrm{~g} / \mathrm{L}$. On the other hand, Prado et al. [4] obtained higher furfural concentration after SCW hydrolysis of coconut husk at higher SF condition, which was $0.75 \mathrm{~g} / \mathrm{L}$ at $212{ }^{\circ} \mathrm{C}$ for $30 \mathrm{~min}$ (SF of 4.77 ). These results revealed that furfural content ob-

Table 2. Analysis of Variance (ANOVA) for sugar concentration on SCW process at mild condition.

\begin{tabular}{|c|c|c|c|c|c|c|}
\hline Source & $\mathrm{DF}$ & Sec. SS & Adj. SS & Adj. Ms & $F$ & $P$ \\
\hline Regression & 9 & 69.3583 & 69.3583 & 7.7065 & 12.30 & 0.000 \\
\hline Linear & 3 & 62.7970 & 62.7970 & 20.9323 & 33.41 & 0.000 \\
\hline Pressure & 1 & 0.0768 & 0.0768 & 0.0768 & 0.12 & 0.730 \\
\hline Temperature & 1 & 33.3183 & 33.3183 & 33.3183 & 53.17 & 0.000 \\
\hline Time & 1 & 29.4019 & 29.4019 & 29.4019 & 46.92 & 0.000 \\
\hline Square & 3 & 1.6915 & 1.6915 & 0.5638 & 0.90 & 0.459 \\
\hline Pressure*Pressure & 1 & 0.1278 & 0.2347 & 0.2347 & 0.37 & 0.547 \\
\hline Temperature*Temperature & 1 & 0.4504 & 0.5629 & 0.5629 & 0.90 & 0.355 \\
\hline Time*Time & 1 & 1.1134 & 1.1134 & 1.1134 & 1.78 & 0.198 \\
\hline Interaction & 3 & 4.8698 & 4.8698 & 1.6233 & 2.59 & 0.081 \\
\hline Pressure*Temperature & 1 & 2.7967 & 2.7967 & 2.7967 & 4.46 & 0.047 \\
\hline Pressure*Time & 1 & 0.2945 & 0.2945 & 0.2945 & 0.47 & 0.501 \\
\hline Temperature*Time & 1 & 1.7786 & 1.7786 & 1.7786 & 2.84 & 0.108 \\
\hline Residual Error & 20 & 12.5323 & 12.5323 & 0.6266 & & \\
\hline Lack-of-Fit & 3 & 4.0650 & 4.0650 & 1.3550 & 2.72 & 0.077 \\
\hline Pure Error & 17 & 8.4673 & 8.4673 & 0.4981 & & \\
\hline Total & 29 & 81.8907 & & & & \\
\hline
\end{tabular}

Note: The values in bold are statistically significant (significance level of 95\%) 
tained after subcritical hydrolysis was proportional to the SF level. The higher the SF level, the higher the furfural produced. The high furfural content should be avoided because it can inhibit the cell growth of microorganisms in the further bioprocesses.

\subsection{Comparison between $\mathrm{N}_{2}$ and $\mathrm{CO}_{2}$ as the} Pressurizing Gas

Figure 4 depicts the degraded holocellulose after SCW hydrolysis using $\mathrm{N}_{2}$ and $\mathrm{CO}_{2}$ as the pressurizing gas. From Figure 4, working with both $\mathrm{N}_{2}$ and $\mathrm{CO}_{2}$, it is presented that at low to mild SF, the conversion of hemicellulose is higher than the cellulose sugars, which may occur due to decomposition rate of hemicellulose was faster than cellulose [44]. These conditions may be caused by the presence of a short polymer chain of the hemicellulose. The chain was broken down easily by severe conditions [5]. On
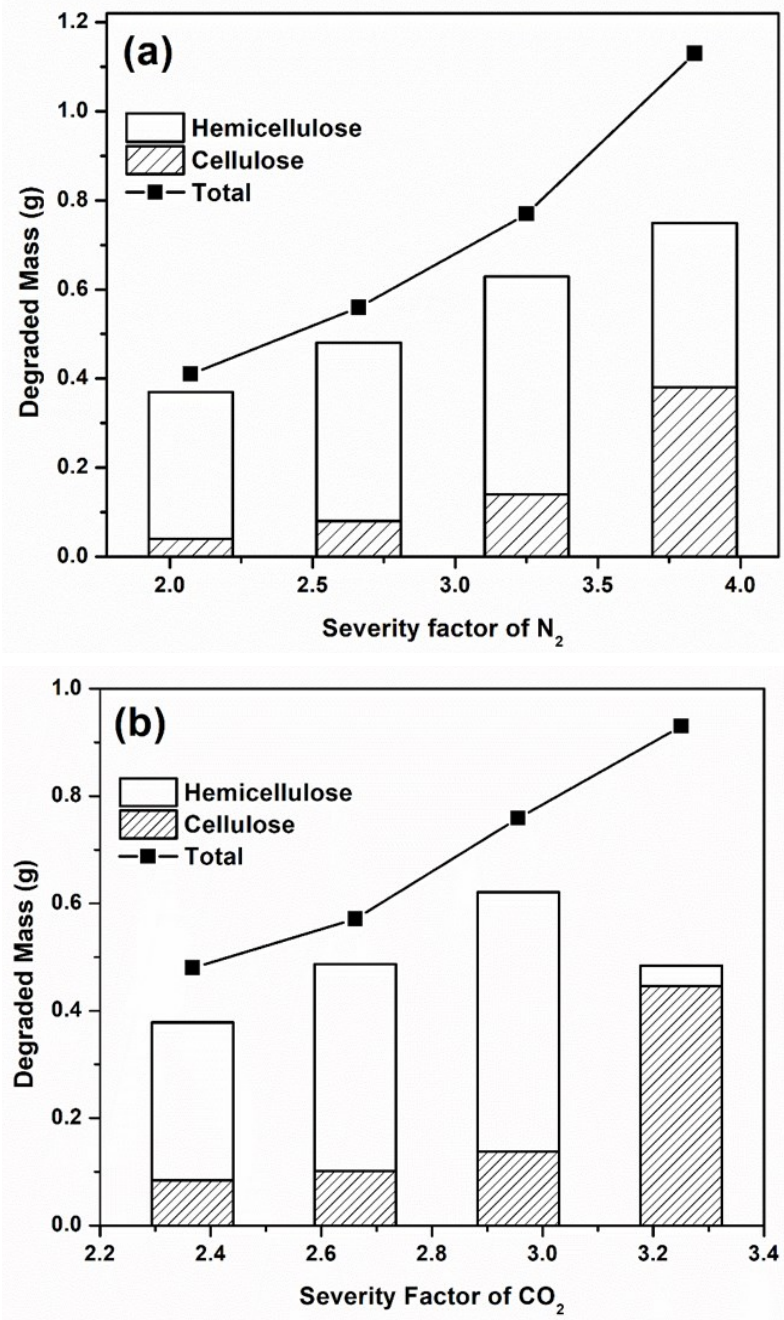

Figure 4. The degraded holocellulose after SCW hydrolysis using (a) nitrogen and (b) carbon dioxide. the other hand, it was found that cellulose was hydrolyzed into monomeric sugar under the mild to high severity condition. Determination of the optimum condition in this SF range became an important matter because, at high SF condition (higher temperature and longer reaction time), the hydrolysis rates of cellulose was slower than glucose or oligomers decomposition [44,45]. This condition should be avoided to obtain high sugar yield and low sugar degradation.

Figure 4 interprets decomposed hemicellulose and cellulose after hydrothermal treatment. Nitrogen, as shown in Figure 4a had a different character compared to carbon dioxide (in Figure $4 \mathrm{~b}$ ) on the hydrolysis of biomass. Hemicellulose and cellulose compounds were hydrolyzed faster in carbon dioxide than nitrogen at low severity. This phenomenon could be explained that carbon dioxide as the pressurizing gas was dissolved in the medium and reacted with water resulting in the formation of a weak acid like carbonic acid that acts as a catalyst [46].

Under pressurizing gas of carbon dioxide, the extracted hemicellulose increased significantly about $64.26 \%$ at low SF from 2.3 to 2.96 . However, the extracted hemicellulose decreased by about $22.05 \%$ as increasing severity at mild SF. This result was in agreement with the work by [47]. The hemicellulose degradation increased during the low to mild SF and then decreased as increasing SF value. As the severity of the pretreatment conditions increased, xylose would be degraded into furfural [5].

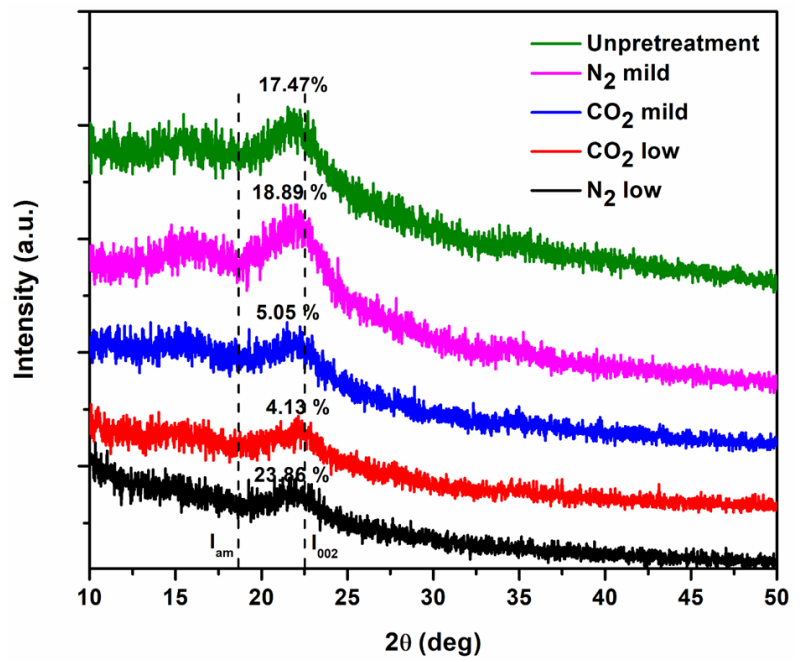

Figure 5. The crystallinity index (CrI) values of the solids after SCW hydrolysis in the severity conditions used. 


\subsection{Characterization of Solid Residue}

The crystallinity index (CrI) values of the solids are analyzed in this study (See Figure 5). The native solid had a CrI of $17.47 \%$. The pretreated sample using nitrogen had $\mathrm{CrI}$ value higher than the native solid, namely 18.89 and $23.86 \%$ at mild and low severity levels, respec-
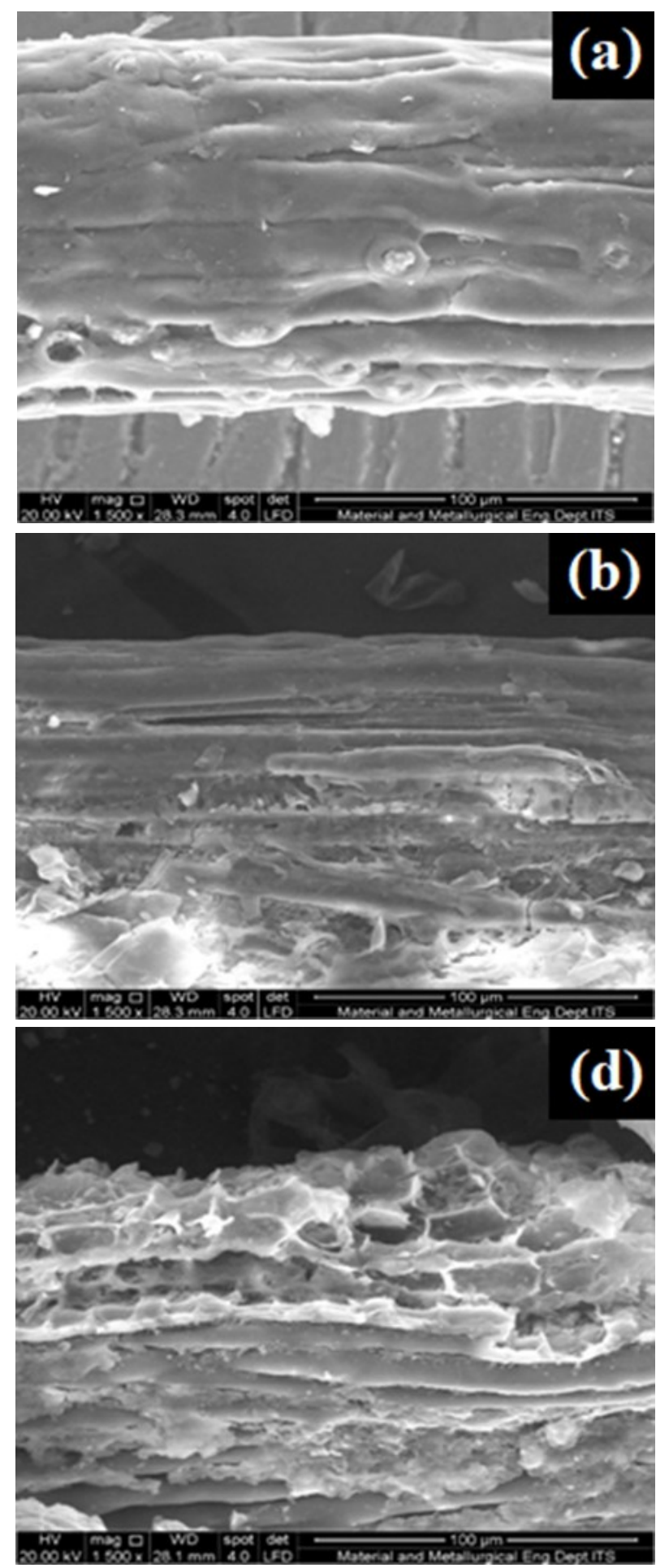

tively. The increase in CrI of the pretreated solid may be due to the breakdown or dissolution part of amorphous hemicellulose and lignin during SCW treatment. Nevertheless, this condition was not strong enough to destroy the crystallinity of the cellulose [44]. On the other hand, the CrI of the SCW using carbon dioxide decreased to 5.05 and $4.13 \%$ at mild and low severity. This CrI decrease indicated that some part of the crystalline structures in cellulose was destroyed [49]. From the results, it revealed that there was no alteration and shifting of the symmetry of the XRD patterns following SCW treated. This phenomenon indicates that after SCW applied, there was only the change of CrI value without dilation of the crystalline structure of cellulose [50].

Scanning Electron Microscopy (SEM) analysis was conducted to compare morphological changes in coconut husk before and after SCW using $\mathrm{N}_{2}$ and $\mathrm{CO}_{2}$ (See Figure 6). The structure of untreated lignocellulose is smooth, tight, and contiguous as shown in Figure 6a. Coconut

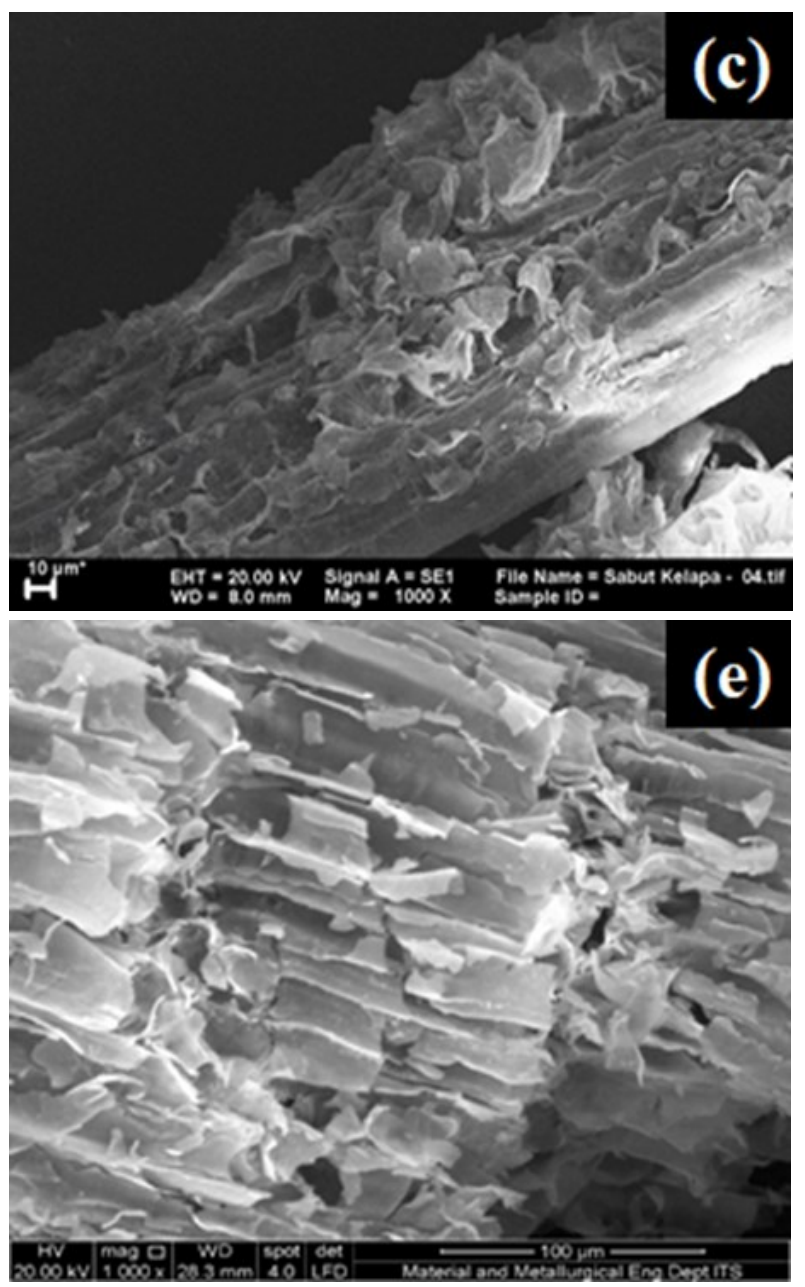

Figure 6. SEM figures of coconut husk solid before (a) and after SCW using $\mathrm{N}_{2}$ and $\mathrm{CO}_{2}$ at low (b and c) and mild severity conditions ( $d$ and e), respectively. 
husk was cracked after the SCW process. Putrino et al. [7] showed that coconut fiber subjected supercritical $\mathrm{CO}_{2}$ underwent the increase of porosity and the reduction of the hydrogen bond between lignin and cellulose. After SCW applied using both $\mathrm{N}_{2}$ and $\mathrm{CO}_{2}$, as shown in Figure 6 (b-e), the wall structure was changed to become more rough, hollow, and amorphous. Compared to SCW using $\mathrm{N}_{2}$ in the low and mild SF conditions, the structural changes were more severe when $\mathrm{CO}_{2}$ gas was used. This phenomenon may be related to the compressibility of gases. The rupture of this structure reveals that SCW disintegrated the lignocellulose cell wall. These structural alterations increase the accessibility of enzymes to expose cellulose, yielding a high sugar production in the enzymatic hydrolysis process $[32,50]$.

\subsection{Effect of SCW Severity on Enzymatic Hy- drolysis at Low SF}

Cellulase is a complex enzyme that gradually hydrolyze the cellulose chain into glucose [51]. The three components identified in the cellulase enzyme are endoglucanases (EG), exoglucanases / cellobiohydrolases (CBH), and $\beta$-glucosidase (BG) [52]. The hydrolysis of cellulose to glucose goes through a multi-step reaction, namely the cleavage of $\beta-1,4$ bonds on the cellulose fiber chains by EG and the degradation of crystalline cellulose by $\mathrm{CBH}$ into shortchain oligosaccharides and cellobiose, and the hydrolysis of cellobiose and oligosaccharides into glucose by BG [53-55].

Pino et al. [56] reported the catalytic deactivation of a commercial cellulase from Trichoderma reesei on the hydrolysis of agave bagasse

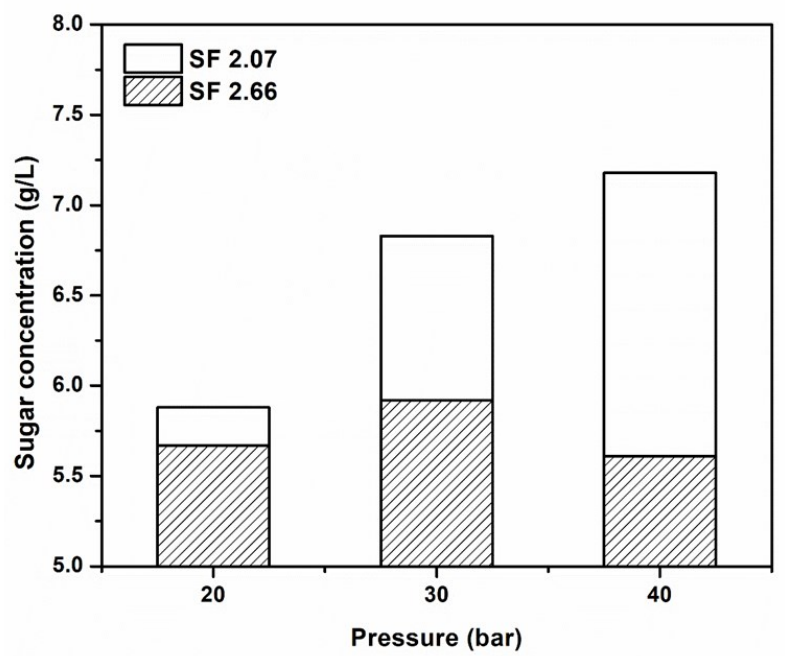

Figure 7. The effect of severity condition on the sugar concentration after enzymatic hydrolysis. which hydrothermally pretreated. The study revealed that the efficiency of the catalytic performance of cellulase underwent a drastic drop on the glucose production after the fast-initial hydrolysis rate. The decrease was induced by deactivation of $\beta$-glucosidase owing to lignin adsorption and feedback inhibition owing to an accumulation of cellobiose.

Xylanase is a group of enzymes that have the ability to synergistically hydrolyze xylan into simple sugars which involve a different mechanism of action of the enzyme consortium [57,58]. Xylanases can be classified based on the hydrolyzed substrates, namely endo-1,4- $\beta$ xylanase, $\beta$-xylosidase, $\alpha$-arabinofuranosidases and esterases. The following is a complete breakdown by the action of several hydrolytic xylanases; Endo-1,4- $\beta$-xylanase attacks glycosidic bonds releasing xylo-oligosaccharides, $\beta$ xylosidase hydrolyzes short-chain xylooligosaccharides and cellobiose to xylose, $\alpha$ arabinofuranosidases removes arabinose from xylan backbone, $\alpha$-Glucuronidase cleaves $\alpha-1,2$ glycosidic linkages, and Esterases acts on the ester linkages of xylan [59].

ANOVA analysis of sugar obtained from enzymatic hydrolysis after SCW applied at low SF exhibited that pressure had a significant effect on the sugar yield (data not shown). Therefore, in this work, enzymatic hydrolysis was utilized only on the solid pretreated by SCW at low SF in different pressure. Figure 7 shows the effect of SCW on sugar concentration after the enzymatic hydrolysis. At low severity factor (SF 2.07), sugar concentration increased as adding pressure. Around this SF value, the SCW pressure gave a significant effect $(P<0.05)$ on the sugar concentration due to the enlarging porosity of lignin, yielding a decreasing of hindrance between enzyme and substrate [50].

On the other hand, sugar concentration decreased as increasing pressure under mild SF (SF 2.66). This fact may be related to the escalation of the SCW temperature. Increasing temperature gave a significant impact because the sugar was hydrolyzed into the degraded compound. At the higher temperatures (mild $\mathrm{SF}$ ), further degradation of lignocellulosic biomass produced furan compounds that can inhibit the enzymatic process [16].

\section{Conclusions}

This work revealed that at low severity range, the pressure of nitrogen as pressurizing gas had a significant effect both to increase sugar production and enhance the enzymatic process digestibility. At mild severity, 
temperature and reaction time influenced a considerable impact. On the enzymatic hydrolysis process, the pressure had a significant impact on sugar production. This study recommends the SCW and enzymatic hydrolysis at a mild severity level as a promising method for sugar production before the fermentation process.

\section{Acknowledgments}

This work was supported financially by the Ministry of Research, Technology, \& Higher Education of the Republic of Indonesia.

\section{References}

[1] Kumar, G., Shobana, S., Nagarajan, D., Lee, D.J., Lee, K.S., Lin, C.Y., Chen, C.Y., Chang, J.S. (2018). Biomass based hydrogen production by dark fermentation - recent trends and opportunities for greener processes. Current Opinion in Biotechnology, 50, 136-145. DOI: 10.1016/j.copbio.2017.12.024.

[2] Ren, N.Q., Zhao, L., Chen, C., Guo, W.Q., Cao, G.L. (2016). A review on bioconversion of lignocellulosic biomass to $\mathrm{H}_{2}$ : Key challenges and new insights. Bioresource Technology, $215, \quad 92-99 . \quad$ D O I : 10.1016/j.biortech.2016.03.124.

[3] Widjaja, A., Agnesty, S.Y., Sangian, H.F., Gunawan, S. (2015). Application of ionic liquid [DMIM]DMP pretreatment in the hydrolysis of sugarcane Bagasse for biofuel production. Bulletin of Chemical Reaction Engineering \& Catalysis, 10(1), 70-77. DOI: 10.9767/bcrec.10.1.7143.70-77.

[4] Prado, J.M., Forster-Carneiro, T., Rostagno, M.A., Follegatti-Romero, L.A., Maugeri Filho, F., Meireles, M.A.A. (2014). Obtaining sugars from coconut husk, defatted grape seed, and pressed palm fiber by hydrolysis with subcritical water. Journal of Supercritical Fluids, 89, 89-98. DOI: 10.1016/j.supflu.2014.02.017.

[5] Muharja, M, Junianti, F., Ranggina, D., Nurtono, T., Widjaja, A. (2018). An integrated green process: Subcritical water, enzymatic hydrolysis, and fermentation, for biohydrogen production from coconut husk. Bioresource Technology, 249, 268-275. DOI: 10.1016/j.biortech.2017.10.024.

[6] Sangian, H.F., Kristian, J., Rahma, S., Dewi, H.K., Puspasari, D.A., Agnesty, S.Y., Gunawan., S., Widjaja, A. (2015). Preparation of reducing sugar hydrolyzed from high-lignin coconut coir dust pretreated by the recycled ionic liquid [mmim][dmp] and combination with alkaline. Bulletin of Chemical Reaction Engineering \& Catalysis, 10(1), 8-22. DOI: 10.9767/bcrec.10.1.7058.822.
[7] Putrino, F.M., Tedesco, M., Bodini, R.B., Oliveira, A.L.de. (2020). Study of supercritical carbon dioxide pretreatment processes on green coconut fiber to enhance enzymatic hydrolysis of cellulose. Bioresource Technology, $\begin{array}{lllllllll}30 & 0\end{array} \quad 123387$ D O I : 10.1016/j.biortech.2020.123387.

[8] Fachri, B.A., Rizkiana, M.F., Muharja, M. (2020). A Kinetic Study on Supercritical Carbon-dioxide Extraction of Indonesian Trigona sp. Propolis. IOP Conf. Series: Materials Science and Engineering, 742(012001), 1-5. DOI: 10.1088/1757-899X/742/1/012001.

[9] Batista M.D., Montes de Oca-Vásquez, G., Vega-Baudrit, J.R., Rojas-Álvarez, M., CorralesCastillo, J., Murillo-Araya, L.C. (2020). Pretreatment methods of lignocellulosic wastes into value-added products: recent advances and possibilities. Biomass Conversion and Biorefinery. DOI: 10.1007/s13399-020-00722-0.

[10] Lachos-Perez, D., Baseggio, A.M., TorresMayanga, P.C., Ávila, P.F., Tompsett, G.A., Marostica, M., Goldbeck, R., Timko, M.T., Rostagno, M., Martinez, J., Forster-Carneiro, T. (2020). Sequential subcritical water process applied to orange peel for the recovery flavanones and sugars. Journal of Supercritical Fluids, 160, 104789. DOI: 10.1016/j.supflu.2020.104789.

[11] Abaide, E.R., Ugalde, G., Di Luccio, M., Moreira, R.de F.P.M., Tres, M.V., Zabot, G.L., Mazutti, M.A. (2019). Obtaining fermentable sugars and bioproducts from rice husks by subcritical water hydrolysis in a semicontinuous mode. Bioresource Technology, $272, \quad 510-520 . \quad$ D O I : 10.1016/j.biortech.2018.10.075.

[12] Xu, Y., Wang, P., Xue, S., Kong, F., Ren, H., Zhai, H. (2020). Green biorefinery - The ultra-high hydrolysis rate and behavior of Populus tomentosa hemicellulose autohydrolysis under moderate subcritical water conditions. RSC Advances, 10(32), 18908-18917. DOI: 10.1039/d0ra02350g.

[13] Aguirre-Fierro, A., Ruiz, H. A., Cerqueira, M.A., Ramos-González, R., Rodríguez-Jasso, R.M., Marques, S., Lukasik, R.M. (2020). Sustainable approach of high-pressure agave bagasse pretreatment for ethanol production. Renewable Energy, 155, 1347-1354. DOI: 10.1016/j.renene.2020.04.055.

[14] Rasmussen, H., Sørensen, H.R., Meyer, A.S. (2014). Formation of degradation compounds from lignocellulosic biomass in the biorefinery: Sugar reaction mechanisms. Carbohydrate Research, 385, 45-57. DOI: 10.1016/j.carres.2013.08.029.

[15] Sun, S., Sun, S., Cao, X., Sun, R. (2016). The role of pretreatment in improving the enzy- 
matic hydrolysis of lignocellulosic materials. Bioresource Technology, 199, 49-58. DOI: 10.1016/j.biortech.2015.08.061.

[16] Jönsson, L.J., Martín, C. (2016). Pretreatment of lignocellulose: Formation of inhibitory by-products and strategies for minimizing their effects. Bioresource Technology, 199, 103-112. DOI: 10.1016/j.biortech.2015.10.009.

[17] Pedras, B.M., Nascimento, M., Sá-Nogueira, I., Simões, P., Paiva, A., Barreiros, S. (2019). Semi-continuous extraction/hydrolysis of spent coffee grounds with subcritical water. Journal of Industrial and Engineering Chemistry, (2018), 8-11 . D O I : 10.1016/j.jiec.2019.01.001.

[18] Kubota, A.M., Kalnins, R., Overton, T.W. (2018). A biorefinery approach for fractionation of Miscanthus lignocellulose using subcritical water extraction and a modified organosolv process. Biomass and Bioenergy, 111, 52-59. DOI: 10.1016/j.biombioe.2018.01.019.

[19] Yedro, F.M., Grénman, H., Rissanen, J.V., Salmi, T., García-Serna, J., Cocero, M.J. (2017). Chemical composition and extraction kinetics of Holm oak (Quercus ilex) hemicelluloses using subcritical water. The Journal of Supercritical Fluids, 129, 56-62. DOI: 10.1016/j.supflu.2017.01.016.

[20] Fernández, M.A., Rissanen, J., Nebreda, A.P., Xu, C., Willför, S., Serna, J.G., Salmi, T., Grénman, H. (2018). Hemicelluloses from stone pine, holm oak, and Norway spruce with subcritical water extraction - comparative study with characterization and kinetics. Journal of Supercritical Fluids, 133, 647-657. DOI: 10.1016/j.supflu.2017.07.001.

[21] Monlau, F., Sambusiti, C., Barakat, A., Quéméneur, M., Trably, E., Steyer, J., Carrère, H. (2014). Do furanic and phenolic compounds of lignocellulosic and algae biomass hydrolyzate inhibit anaerobic mixed cultures? A comprehensive review. Biotechnology Advances, $32(5), \quad 934-951$. DOI: 10.1016/j.biotechadv.2014.04.007.

[22] Prado, J.M., Lachos-Perez, D., ForsterCarneiro, T., Rostagno, M.A. (2016). Sub- A nd supercritical water hydrolysis of agricultural and food industry residues for the production of fermentable sugars: A review. Food and Bioproducts Processing, 98, 95-123. DOI: 10.1016/j.fbp.2015.11.004.

[23] Batista, G., Souza, R.B.A., Pratto, B., dos Santos-Rocha, M.S.R., Cruz, A.J.G. (2019). Effect of severity factor on the hydrothermal pretreatment of sugarcane straw. Bioresource Technology, 275, 321-327. DOI: 10.1016/j.biortech.2018.12.073.
[24] Zhu, Z., Liu, Z., Zhang, Y., Li, B., Lu, H., Duan, N., Si, B., Shen R., Lu, J. (2016). Recovery of reducing sugars and volatile fatty acids from cornstalk at different hydrothermal treatment severity. Bioresource Technology, $199, \quad 220-227$. D O I : 10.1016/j.biortech.2015.08.043.

[25] Iroba, K.L., Tabil, L.G., Sokhansanj, S., Dumonceaux, T. (2014). Pretreatment and fractionation of barley straw using steam explosion at low severity factor. Biomass and Bioenergy, 66, 286-300. DOI: 10.1016/j.biombioe.2014.02.002.

[26] Kumar, L., Chandra, R., Saddler, J. (2011). Influence of steam pretreatment severity on post-treatments used to enhance the enzymatic hydrolysis of pretreated softwoods at low enzyme loadings. Biotechnology and Bioengineering, 108(10), 2300-2311. DOI: 10.1002/bit.23185.

[27] Lee, J.-W., Jeffries, T.W. (2011). Efficiencies of acid catalysts in the hydrolysis of lignocellulosic biomass over a range of combined severity factors. Bioresource Technology, 102,

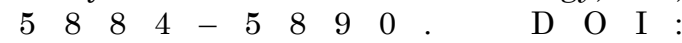
10.1016/j.biortech.2011.02.048.

[28] Torres-Mayanga, P.C., Azambuja, S.P.H., Tyufekchiev, M., Tompsett, G.A., Timko, M.T., Goldbeck, R., Rostagno, M.A., ForsterCarneiro, T. (2019). Subcritical water hydrolysis of brewer's spent grains: Selective production of hemicellulosic sugars (C-5 sugars). The Journal of Supercritical Fluids, 145, 1930. DOI: 10.1016/j.supflu.2018.11.019.

[29] Michelin, M., Ruiz, H.A., Polizeli, M.de L.T.M., Teixeira, J.A. (2018). Multi-step approach to add value to corncob: Production of biomass-degrading enzymes, lignin and fermentable sugars. Bioresource Technology, $247, \quad 582-590 . \quad$ D O I : 10.1016/j.biortech.2017.09.128.

[30] Liang, J., Chen, X., Wang, L., Wei, X., Wang, H., Lu, S., Li, Y. (2017). Subcritical carbon dioxide-water hydrolysis of sugarcane bagasse pith for reducing sugars production. Bioresource Technology, 228, 147-155. DOI: 10.1016/j.biortech.2016.12.080.

[31] Mayanga-Torres, P.C., Lachos-Perez, D., Rezende, C.A., Prado, J.M., Ma, Z., Tompsett, G.T., Timko, M.T., Forster-Carneiro, T. (2017). Valorization of coffee industry residues by subcritical water hydrolysis: Recovery of sugars and phenolic compounds. Journal of Supercritical Fluids, 120, 75-85. DOI: 10.1016/j.supflu.2016.10.015.

[32] Muharja, M., Fadhilah, N., Nurtono, T., Widjaja, A. (2020). Enhancing enzymatic digestibility of coconut husk using nitrogen as- 
sisted-subcritical water for sugar production. Bulletin of Chemical Reaction Engineering \& Catalysis, 15(1), 84-95. DOI: 10.9767/bcrec.15.1.5337.84-95.

[33] Lin, R., Cheng, J., Ding, L., Song, W., Qi, F., Zhou, J., Cen, K. (2015). Subcritical water hydrolysis of rice straw for reducing sugar production with focus on degradation by-products and kinetic analysis. Bioresource Technology, $186, \quad 8-14 . \quad$ D O I : 10.1016/j.biortech.2015.03.047.

[34] Muharja, M., Junianti, F., Nurtono, T., Widjaja, A. (2017). Combined subcritical water and enzymatic hydrolysis for reducing sugar production from coconut husk. AIP Conference Proceedings, $1840, \quad 030004$. https://doi.org/10.1063/1.4982264.

[35] Miller, G.L. (1959). Use of Dinitrosalicylic Acid Reagent for Determination of Reducing Sugar. Analytical Chemistry, 31(3), 426-428. DOI: $10.1021 /$ ac60147a030.

[36] Muharja, M., Umam, D.K., Pertiwi, D., Zuhdan, J., Nurtono, T., Widjaja, A. (2019). Enhancement of sugar production from coconut husk based on the impact of the combination of surfactant-assisted subcritical water and enzymatic hydrolysis. Bioresource Technology, $274, \quad 89-96$. D O I : 10.1016/j.biortech.2018.11.074.

[37] García, R., Pizarro, C., Lavín, A.G., Bueno, J.L. (2014). Spanish biofuels heating value estimation. Part I: Ultimate analysis data. Fuel, 117, 1130-1138. DOI: 10.1016/j.fuel.2013.08.048.

[38] Bilba, K., Arsene, M., Ouensanga, A. (2007). Study of banana and coconut $\mathrm{W}$ bers Botanical composition, thermal degradation, and textural observations. Bioresource Technolog $y, \quad 98, \quad 58-68$. D O I : 10.1016/j.biortech.2005.11.030.

[39] Li, H.Z., Zhang, Z.J., Hou, T.Y., Li, X.J., Chen, T. (2015). Optimization of ultrasoundassisted hexane extraction of perilla oil using response surface methodology. Industrial Crops and Products, 76, 18-24. DOI: 10.1016/j.indcrop.2015.06.021.

[40] Muharja, M, Albana, I., Zuhdan, J., Bachtiar, A., Widjaja, A. (2019). Reducing Sugar Production in Subcritical Water and Enzymatic Hydrolysis using Plackett- Burman Design and Response Surface Methodology. Jurnal Teknik ITS, 8(2), 56-61. DOI: 10.12962/j23373539.v8i2.49727..

[41] Hongdan, Z., Shaohua, X., Shubin, W. (2013). Enhancement of enzymatic saccharification of sugarcane bagasse by liquid hot water pretreatment. Bioresource Technology, 143, 391396. DOI: 10.1016/j.biortech.2013.05.103.
[42] Alimny, A.N., Muharja, M., Widjaja, A. (2019). Kinetics of Reducing Sugar Formation from Coconut Husk by Subcritical Water Hydrolysis. Journal of Physics: Conference Series, 1373, 1-8. DOI: 10.1088/17426596/1373/1/012006.

[43] Prado, J.M., Vardanega, R., Nogueira, G.C., Forster-Carneiro, T., Rostagno, M.A., Maugeri Filho, F., Meireles, M.A.A. (2017). Valorization of Residual Biomasses from the AgriFood Industry by Subcritical Water Hydrolysis Assisted by CO2. Energy and Fuels, 31(3),

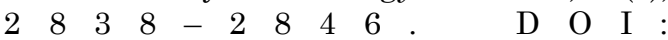
10.1021/acs.energyfuels.6b02670.

[44] Zhang, H., Wu, S. (2015). Pretreatment of eucalyptus using subcritical $\mathrm{CO} 2$ for sugar production. Journal of Chemical Technology and Biotechnology, 90(9), 1640-1645. DOI: 10.1002/jctb.4470.

[45] Mohan, M., Banerjee, T., Goud, V.V. (2015). Hydrolysis of bamboo biomass by subcritical water treatment. Bioresource Technology, $191, \quad 244-252 . \quad$ D O I : 10.1016/j.biortech.2015.05.010.

[46] Santos, M.S.N.do., Zabot, G.L., Mazutti, M.A., Ugalde, G.A., Rezzadori, K., Tres, M.V. (2020). Optimization of subcritical water hydrolysis of pecan wastes biomasses in a semicontinuous mode. Bioresource Technology, $306, \quad 123-129$. D O I : 10.1016/j.biortech.2020.123129.

[47] Yang, T., Wang, J., Li, B., Kai, X., Li, R. (2017). Effect of residence time on two-step liquefaction of rice straw in a $\mathrm{CO}_{2}$ atmosphere: Differences between subcritical water and supercritical ethanol. Bioresource Technology, 229, 143-151. D O I : 10.1016/j.biortech.2016.12.110.

[48] Gonzales, R.R., Sivagurunathan, P., Kim, S.H. (2016). Effect of severity on dilute acid pretreatment of lignocellulosic biomass and the following hydrogen fermentation. International Journal of Hydrogen Energy, 41(46), $\begin{array}{lllllllllllllllll}2 & 1 & 6 & 7 & 8 & - & 2 & 1 & 6 & 8 & 4 & & & \text { D } & \text { O } & \text { I : }\end{array}$ 10.1016/j.ijhydene.2016.06.198.

[49] Yang, W., Wang, H., Zhou, J., Wu, S. (2017). Hydrolysis Kinetics and Structure Changes of Wood Meal in Subcritical Water. ACS Sustainable Chemistry \& Engineering, 5(4), $\begin{array}{llllllllllllll} & 3 & 5 & 4 & 4 & - & 3 & 5 & 5 & 2 & . & \text { D } & \text { O } & \text { I : }\end{array}$ 10.1021/acssuschemeng.7b00300.

[50] Sangian, H.F., Widjaja, A. (2017). Effect of Pretreatment Method on Structural Changes of Coconut Coir Dust. BioResources, 12(4), 8030-8046. DOI: 10.15376/biores.12.4.80308046.

[51] Sindhu, R., Binod, P., Pandey, A. (2016). Biological pretreatment of lignocellulosic bio- 
mass - An overview. Bioresource Technology, $199, \quad 76-82 . \quad$ D O I : 10.1016/j.biortech.2015.08.030.

[52] Brahmachari, G., Demain, A.L., Adrio, J.L. (2016). Biotechnology of Microbial Enzymes: Production, Biocatalysis and Industrial Applications. In Biotechnology of Microbial Enzymes: Production, Biocatalysis and Industrial Applications. London: Elsevier.

[53] Andrić, P., Meyer, A.S., Jensen, P.A., DamJohansen, K. (2010). Reactor design for minimizing product inhibition during enzymatic lignocellulose hydrolysis: I. Significance and mechanism of cellobiose and glucose inhibition on cellulolytic enzymes. Biotechnology Advances, 28(3), 308-324. DOI: 10.1016/j.biotechadv.2010.01.003.

[54] Van Dyk, J.S., Pletschke, B.I. (2012). A review of lignocellulose bioconversion using enzymatic hydrolysis and synergistic cooperation between enzymes - Factors affecting enzymes, conversion and synergy. Biotechnology Advances, $30, \quad 1458-1480$. DOI: 10.1016/j.biotechadv.2012.03.002.

[55] Haldar, D., Sen, D., Gayen, K. (2016). A review on the production of fermentable sugars from lignocellulosic biomass through conventional and enzymatic route - a comparison. International Journal of Green Energy, 13(12),

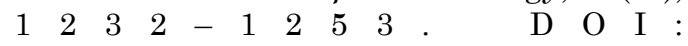
10.1080/15435075.2016.1181075.
[56] Pino, M.S., Rodríguez-Jasso, R.M., Michelin, M., Ruiz, H.A. (2019). Enhancement and modeling of enzymatic hydrolysis on cellulose from agave bagasse hydrothermally pretreated in a horizontal bioreactor. Carbohydrate Polymers, 211, 349-359. DOI: 10.1016/j.carbpol.2019.01.111.

[57] Moreira, L.R.S., Filho, E.X.F. (2016). Insights into the mechanism of enzymatic hydrolysis of xylan. Applied Microbiology and Biotechnology, 100(12), 5205-5214. DOI: 10.1007/s00253-016-7555-z.

[58] Gírio, F.M., Fonseca, C., Carvalheiro, F., Duarte, L.C., Marques, S., Bogel-Łukasik, R. (2010). Hemicelluloses for fuel ethanol: A review. Bioresource Technology, 101(13), 47754800. DOI: 10.1016/j.biortech.2010.01.088.

[59] Binod, P., Gnansounou, E., Sindhu, R., Pandey, A. (2019). Enzymes for second generation biofuels: Recent developments and future perspectives. Bioresource Technology Reports, 5, 317-325. DOI: 10.1016/j.biteb.2018.06.005. 